\title{
Plant guttation water as a potential route for pesticide exposure in honey bees: a review of recent literature
}

\author{
Amelie Schmolke ${ }^{1}$, Brian $\mathrm{KeARNS}^{1}$, Bridget O’NeILL ${ }^{2}$ \\ ${ }^{1}$ Waterborne Environmental Inc., Leesburg, VA, USA \\ ${ }^{2}$ DuPont Crop Protection, Wilmington, DE, USA
}

Received 1 February 2018 - Revised 7 June 2018 - Accepted 3 August 2018

\begin{abstract}
Because honey bees periodically collect water, guttation water from treated crops has been suggested as a potential exposure route to systemic pesticides. We reviewed studies that were published in the scientific literature since a previous review of the topic. We identified several studies that reported residue levels of pesticides in guttation water. However, few studies addressed guttation water as a potential exposure route to honey bees. In these studies, no significant effects on honey bee colony health or overwintering survival were observed when colonies were located within fields of treated crops during guttation periods. The previous and current review suggests that exposure to pesticides via guttation water alone is unlikely to negatively affect honey bee colonies. A better understanding of water foraging by honey bees would be needed to address whether guttation water could represent a relevant exposure route of honey bees to systemic pesticides.
\end{abstract}

guttation / honey bees / pesticide risk assessment / neonicotinoids

\section{INTRODUCTION}

Honey bee (Apis mellifera L.) colony losses have recently attracted attention in the scientific literature and from the general public (Neumann and Carreck 2010; Clermont et al. 2015; Seitz et al. 2015). Multiple factors have been implicated in the observed losses, including mite infestations, diseases, and land-use changes. In addition, pesticides, particularly systemic pesticides such as neonicotinoid insecticides, were raised as a potential factor in the losses because honey bees may be exposed to pesticides through various routes (Thompson 2010). Residues of neonicotinoid pesticides have been observed in nectar and pollen of treated crops, implicating nectar and pollen as potential routes of neonicotinoid insecticide exposure to honey bees (Pilling et al. 2013; EFSA

Corresponding author: A. Schmolke, schmolkea@waterborne-env.com Manuscript editor: Monique Gauthier
2013; USEPA 2014; Codling et al. 2016). In addition to nectar and pollen, treated crops may also produce guttation water, which has been discussed as potential additional exposure route (Girolami et al. 2009; Thompson 2010).

Nectar and pollen are collected by honey bees for food and are stored in the hive in designated cells. Pollen provides the protein source for brood rearing while nectar provides the source of sugar for energy as consumed by larvae and adult bees in the colony. Nectar is stored as honey over extended time periods for provision of the colony during the winter or times of low forage availability. Nectar can also function as a water source to produce larval food, and for cooling of the hive during high ambient temperatures. Nectar contains $35-80 \%$ water while honey is concentrated to around $75 \%$ sugar (Seeley 1995). However, honey bees rely directly on water foraging when fresh nectar for larval food production is scarce as can be the case in early spring, and when the optimal hive temperature of around $35{ }^{\circ} \mathrm{C}$ is exceeded (Lindauer 1955). 
Water collection is conducted by specialized foragers. The foraging effort of water foragers is regulated by demand in the hive, which may include thirst of the water foragers themselves as well as begging behavior of receiving bees in the hive (Kühnholz and Seeley 1997, Ostwald et al. 2016). Water may be added to uncapped nectar cells, and water foragers may retain water in their crops while not foraging (Ostwald et al. 2016). The regulation of water foraging as well as preferences for particular water sources is less well understood than foraging for nectar and pollen. Bee flight is energetically costly and, accordingly, foragers strongly prefer water sources close to the hive to minimize energy expense (Kovac et al. 2010). Water sources may include, e.g., small water bodies, dew, and guttation water.

Guttation refers to the secretion of fluid from leaves and occurs in a wide range of plant species. High rates of water absorption by plants from the soil under conditions with low transpiration lead to the exudation of fluid from pores in leaves. Transpiration is low under high humidity or when stomata are closed in darkness. In combination with wet and warm soils, guttation can be profuse. Organic and inorganic solutes found in the xylem of a plant are partially absorbed in the pores (hydathodes), leading to lower solute concentrations in guttation fluid (Singh 2013). The timing and occurrence of guttation is highly variable based on climatic region and plant species in question. It is frequently observed in the spring in common crops such as oilseed rape and maize (Joachimsmeier et al. 2011b) and in lawn grasses (Singh 2013). Because of concerns about potential exposure to systemic pesticides through water foraging, Girolami et al. (2009) measured residues of neonicotinoids in guttation water samples from corn seedlings grown from neonicotinoidtreated seeds and fed the guttation water (spiked with sugar) to honey bees in the laboratory. Neonicotinoid concentrations in the guttation water samples reached levels toxic to honey bees, raising concerns that guttation water from treated crops could represent a relevant route of exposure to systemic insecticides. However, Girolami et al. (2009) did not assess whether honey bees foraging for water collect guttation water, and whether effects on colonies from guttation water exposure can be observed in the field.
To address these questions, Pistorius et al. (2011) provided a review of published and unpublished studies on guttation water from crops and the potential effects of residues in guttation water on honey bees. The authors compiled relative occurrences of guttation in several common crops and described guttation timing and pesticide residue levels found. All reviewed studies were focused on neonicotinoid pesticides. Corn (maize) was identified as the "worst-case" crop in this context because the highest residue levels were observed in its guttation water and because corn produces high volumes of guttation water in its seedling stage (spring and early summer). Residue levels of neonicotinoids toxic to honey bees were observed in guttation water in multiple studies (Pistorius et al. 2011). High honey bee mortalities were observed in a semi-field study (also referred to as a "tunnel study") that used guttation as the exposure route. In the experimental setup of the semi-field study, water foraging by the bees was limited to guttation water from corn. When an additional water source without residues was provided in the tunnel, bee mortalities did not differ from the controls. In three field studies included in the review, honey bee colonies were placed next to treated corn or wheat fields during the guttation period. The bees in the field studies were not restricted in their foraging, and water collection from water sources other than crop guttation could not be excluded. Occasional spikes in dead bee numbers were observed at some of the hives placed next to treated corn fields, but no longterm effects on colony health or strength were found. An effort was made to observe honey bees collecting guttation water from the crops, but no instances were observed. The authors concluded that the potential risk from guttation water to honey bee colonies mainly depends on the distance from a colony to a treated crop. Xylem mobility of the compound, persistence, toxicity to bees, mode of action, and crop type should also be considered as criteria to assess the potential for exposure to honey bees. The authors of the review recommended further research to assess potential risk from guttation and to gain a better understanding of water foraging by honey bees.

In this review, we present an overview of studies that address guttation water as potential 
pesticide exposure route to honey bees published in the scientific literature since the review by Pistorius et al. (2011). We included articles in our review if they presented original data on pesticide residue levels in guttation water or the usage or effects of guttation water on honey bees. We provide conclusions how the insights from the studies may inform potential risks from exposed guttation water to honey bees.

\section{PESTICIDE RESIDUE LEVELS IN GUTTATION WATER}

Studies found as part of this review all focused on crops treated with neonicotinoid pesticides. Seed treatment was the most prevalent application method used. Exceptions were the study by Hoffmann and Castle (2012) where drench application was used, one of the studies presented in Nikolakis et al. (2014) that used in-furrow applications, Larson et al. (2015) where neonicotinoids were applied to turfgrass as a surface spray and watered in, and McCurdy et al. (2017) where turfgrass was treated by sub-irrigation or foliar spray. Neonicotinoid compounds applied were imidacloprid, thiamethoxam, and clothianidin. In the study reported by Tapparo et al. (2011), other pesticides were also applied, but no residues above the quantification limit (e.g., LOQ = $17 \mu \mathrm{g} / \mathrm{L}$ for fipronil) were detected in guttation water. Marzaro et al. (2011) measured clothianidin residues in guttation water from untreated corn after contamination by dust from planting of treated seeds in an adjacent field. We included this study in our evaluation as guttation water was addressed. However, the residue levels measured are not representative for seed-treated corn.

Crops studied for guttation water residue levels included corn (Zea mays), oilseed rape (Brassica napus), cantaloupe (Cucumis melo), winter cereal crops, and sugar beets (Beta vulgaris). In addition, two studies focused on turf grass (Larson et al. 2015; McCurdy et al. 2017). For the purposes of this review, we will refer to turf grass as a crop.

Samples of guttation water were collected from these crops, and either average or maximum residue levels of the applied neonicotinoids were reported (Table I). For the three neonicotinoids included in the reviewed studies, residue levels in guttation water were highest in corn (Table I). Tapparo et al. (2011) measured concentrations of three neonicotinoids in guttation water collected from the tops of leaves and from the crown cups. They report the following ranges of concentrations measured in guttation water collected during the first 6 days after emergence of corn seedlings: imidacloprid concentrations ranged from $8.2 \mathrm{mg} / \mathrm{L}$ to a maximum reported concentration of $345.8 \mathrm{mg} /$ $\mathrm{L}$, clothianidin ranged from $7.3 \mathrm{mg} / \mathrm{L}$ to a maximum detection of $101.7 \mathrm{mg} / \mathrm{L}$, and thiamethoxam concentrations ranged from 2.9 to $40.8 \mathrm{mg} / \mathrm{L}$.

Neonicotinoid residue levels measured in guttation water from corn seedlings (Tapparo et al. 2011) exceeded residue levels measured in nearly all other crops by a factor of 100 or more (Table I). Only cantaloupe guttation water, measured shortly after soil application, reached residue levels within the ranges of concentrations measured for corn (maximum imidacloprid concentration of $37.35 \mathrm{mg} / \mathrm{L}$ measured; Hoffmann and Castle 2012). In one of the studies addressing winter cereals, the maximum measured residue levels were 6.7 and $8.5 \mathrm{mg} / \mathrm{L}$ for imidacloprid and clothianidin, respectively (Nikolakis et al. 2014). Peak residue levels in guttation water from sugar beet of $0.658,9.043$, and $2.018 \mathrm{mg} / \mathrm{L}$ were observed for imidacloprid, clothianidin, and thiamethoxam, respectively (Wirtz et al. 2018).

Residue levels in guttation water from seedtreated corn and oilseed rape declined with time following seedling emergence (Pistorius et al. 2011). Seasonal variations in residue levels in guttation water are potentially important, as water foraging frequency by honey bees changes over the year (Lindauer 1955). Nikolakis et al. (2014) presented two studies where residue levels in guttation water sampled in the fall and the following spring were compared. Maximum concentrations of clothianidin and imidacloprid were higher during fall vs. spring guttation events in winter oilseed rape (clothianidin, $0.41 \mathrm{mg} / \mathrm{L}$ in autumn; $0.02 \mathrm{mg} / \mathrm{L}$ in spring) as well as winter cereals (imidacloprid, $6.7 \mathrm{mg} / \mathrm{L}$ in autumn; $0.068 \mathrm{mg} / \mathrm{L}$ in spring; clothianidin, $8.5 \mathrm{mg} / \mathrm{L}$ in autumn; $0.15 \mathrm{mg} / \mathrm{L}$ in spring).

In three studies, the authors examined how pesticide concentrations in guttation water change over time after planting or spray application. 


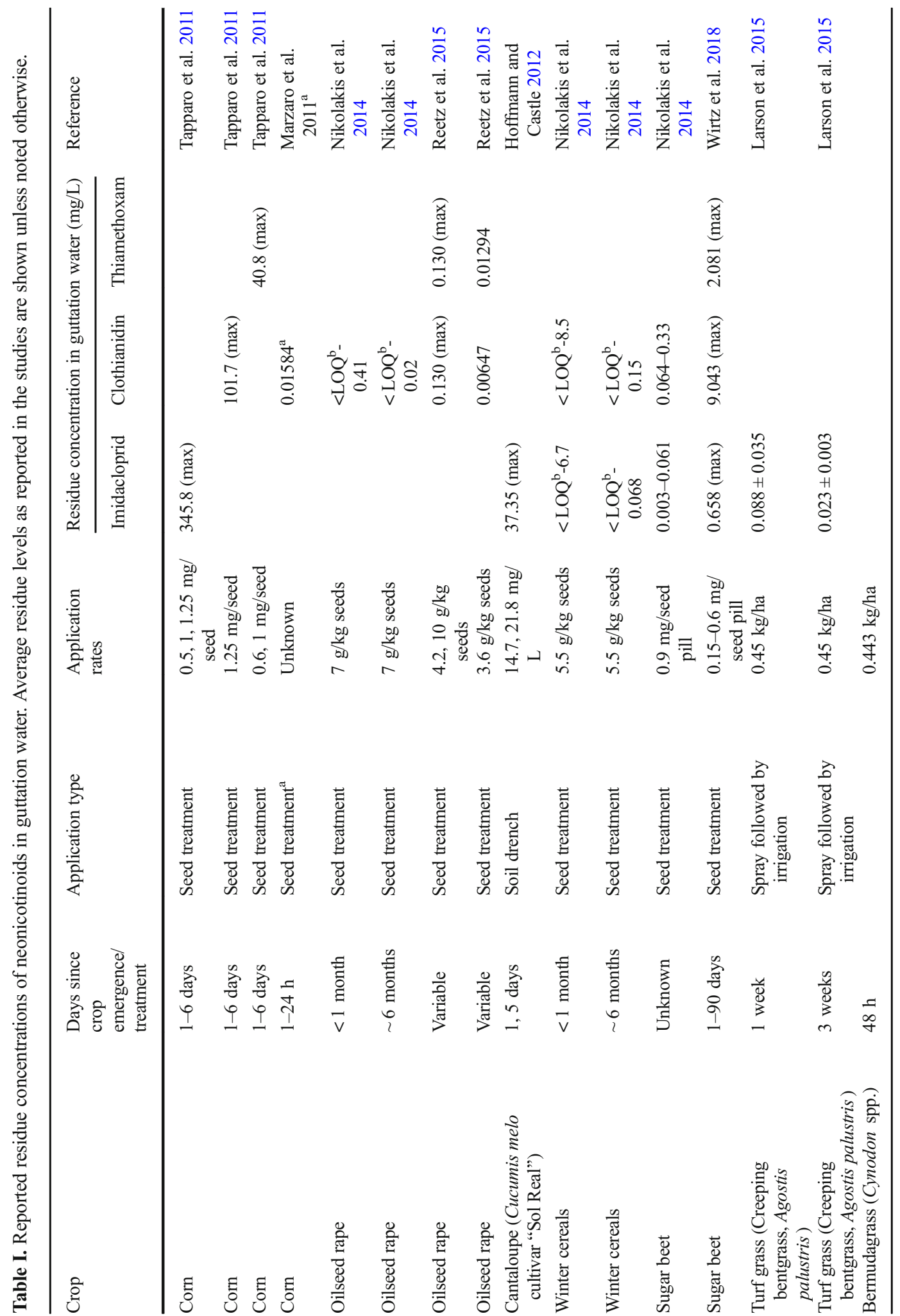




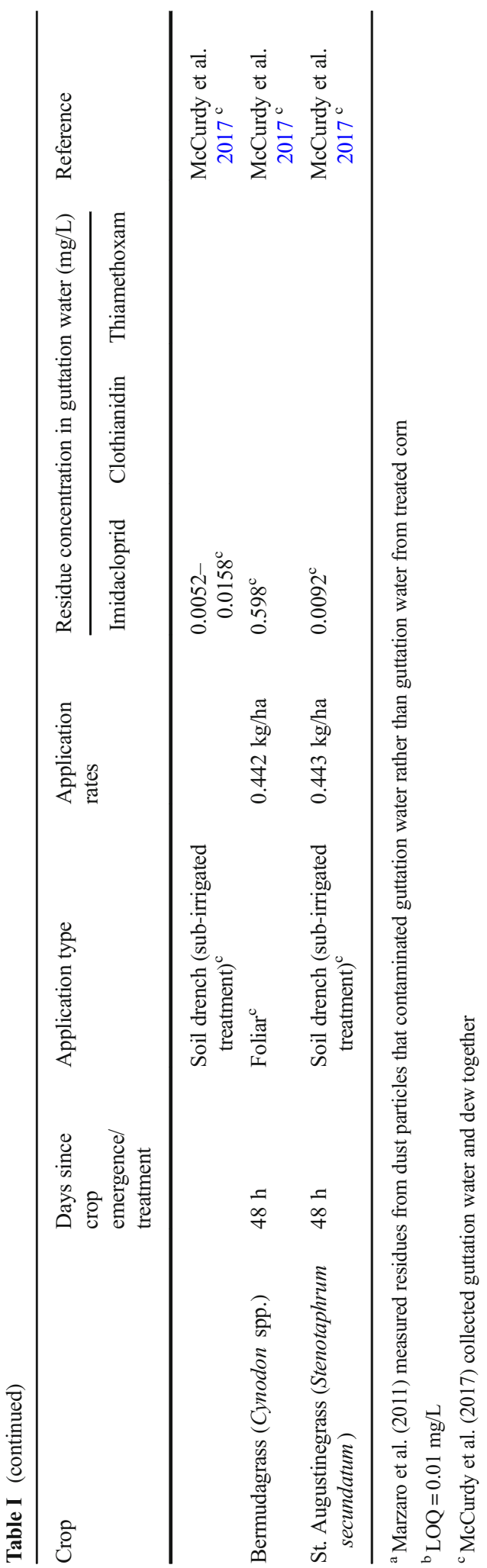

Tapparo et al. (2011) assessed the concentrations of the three neonicotinoids between days 1-20 after seedling emergence of corn plants from coated seeds and found the highest concentrations (average concentrations on day 1 for imidacloprid, $80.87 \mathrm{mg} / \mathrm{L}$; clothianidin, $35.99 \mathrm{mg} / \mathrm{L}$; thiamethoxam, $24.29 \mathrm{mg} / \mathrm{L}$ ) immediately after emergence followed by a decline over the sampling period to a low 8-10 days after planting (average concentrations on days $8-10$ for imidacloprid, $17.3 \mathrm{mg} / \mathrm{L}$; clothianidin, $8.82 \mathrm{mg} /$ $\mathrm{L}$; thiamethoxam, $3.55 \mathrm{mg} / \mathrm{L}$ ). Interestingly, between days 11-19, concentrations increased again (average concentrations on days 11-19 for imidacloprid, $60.13 \mathrm{mg} / \mathrm{L}$; clothianidin, $31.64 \mathrm{mg} / \mathrm{L}$; thiamethoxam, $8.32 \mathrm{mg} / \mathrm{L}$ ). The increase in concentrations after day 10 was attributed to increased water evaporation concentrating solutes within the plant resulting in increased chemical concentrations.

Wirtz et al. (2018) collected guttation water from sugar beet plants over a period of 90 days after emergence. The highest concentrations of neonicotinoids were measured in early growth stages (BBCH 11-19). Maximum measured residue level of imidacloprid was $0.658 \mathrm{mg} /$ $\mathrm{L}, 9.043 \mathrm{mg} / \mathrm{L}$ of clothianidin, and $2.081 \mathrm{mg} / \mathrm{L}$ thiamethoxam. Residue levels fell below the limit of detection (LOD $\leq 0.005 \mathrm{mg} / \mathrm{L}$ for both substances) in later growth stages (BBCH 38). In addition, Wirtz et al. (2018) found higher guttation occurrence in sugar beet with increasing humidity, and highest occurrences of guttation in the crop at temperatures between 10 and $14{ }^{\circ} \mathrm{C}$.

In a study of turf grass, Larson et al. (2015) assessed differences between concentrations at 1 week after application (spraying) and 3 weeks after application. Peak values were seen 1 week after application of imidacloprid $(0.088 \mathrm{mg} / \mathrm{L})$ and decreased over time $(0.023 \mathrm{mg} / \mathrm{L} 3$ weeks after application).

The findings that residue concentrations in guttation water decline with time since planting (for seed-treated crops) or pesticide application (for other application types) are in line with the trends reported by Pistorius et al. (2011). The seasonal difference in residue levels in guttation water from winter cereals 
and winter oilseed rape as reported by Nikolakis et al. (2014) is also driven by time since the emergence of the treated crops.

\section{USAGE OF GUTTATION WATER BY HONEY BEES}

There are several water sources available for foraging honeybees, including water bodies (e.g., puddles and ponds), dew, and guttation water. Whether guttation water is collected by bees depends on the availability of alternative water sources during crop guttation, the cooccurrence of guttation by crops and water needs of bees, the time of day that guttation occurs, and the distance to potential sources of guttation water.

In the study by Joachimsmeier et al. (2011a), honey bee activity was recorded in small patches in experimental fields of oilseed rape and cereal crops between early April and early May (when guttation by the crops was highest). Honey bee colonies were placed in the experimental fields for the study period. The authors observed a small number of honey bees actively collecting water from guttation, dew, or rain drops from the crops. Due to the low sample size, no preference for a water source could be determined, but more honey bees were observed close to the study hives than at larger distances. In the studies reported by Nikolakis et al. (2014), honey bee colonies were placed in treated fields. It was observed that honey bee flight activity and guttation of crops frequently coincided. Up to $14 \%$ of honey bees observed within crops in spring were collecting guttation water. The percentage of honey bees observed collecting guttation water within crops in the fall was considerably lower (only $1.2 \%$ of bees). The percentages in this study refer to the number of honey bees observed during observation periods within the field. The overall number of honey bees foraging for water was not recorded. Weather conditions were not reported, and relationships between conditions that may favor guttation (high temperature differences between night and day or high humidity) and guttation occurrences in the crops were not studied. These studies suggest that guttation in crops and water foraging in honey bees may commonly co-occur. Honey bees have been observed collecting guttation water from crops, but the frequency of guttation water collection in comparison to the overall water collection by honey bee colonies was not assessed.

\section{EFFECTS ON HONEY BEES FROM GUTTATION WATER USAGE}

Only a few studies included in our review addressed effects on honey bees resulting from guttation water collection (Joachimsmeier et al. 2011a; Nikolakis et al. 2014; Reetz et al. 2015). Reetz et al. (2015) identified honey bee water foragers returning to the hive by the low sugar content of the fluid found in their honey stomachs. Residue levels of thiamethoxam in honey stomachs of water foragers were below toxicity thresholds of the compound determined in laboratory chronic toxicity studies.

Joachimsmeier et al. (2011a) did not detect significant differences in honey bee mortality between periods with and without guttation, or between study hives located in treated or untreated fields of oilseed rape and cereal crops. The mean number of dead bees at colonies located at treated fields of various crops were also not different from control colonies in the studies presented by Nikolakis et al. (2014). Neither study observed effects on colony health from exposure to treated guttating crops.

\section{CONCLUSIONS}

In recent reviews of neonicotinoids and their risk to bees, guttation water is explicitly discussed as a possible route of exposure to honey bees and is addressed in varying levels of detail (Sanchez-Bayo and Goka 2014; Blacquière et al. 2012; Bonmatin et al. 2015; Fairbrother et al. 2014; Krupke and Long 2015; Lundin et al. 2015; Pistorius et al. 2011; Rortais et al. 2017; Wood and Goulson 2017). In a guidance document published by the European Food Safety Authority (EFSA 2013), it is stated that pesticide risk assessment considering exposure via guttation water is necessary because an effect cannot be 
excluded. The U.S. Environmental Protection Agency (USEPA) also stated in a recent white paper that guttation water could be a potentially relevant route of exposure, but that it is uncertain to what degree bees collect guttation water (USEPA 2012), which supported findings of the review by Pistorius et al. (2011).

In our review of more recent articles on this topic, these findings were further confirmed. Residues of neonicotinoids in guttation water from treated corn seedlings can reach levels that are immediately toxic to bees. Residue levels in guttation water from other crops were considerably lower than in corn, but could also reach toxic levels in some cases (e.g., cantaloupe as reported by Hoffmann and Castle 2012). Residue levels were found to be highly variable between samples and declined with time since seedling emergence (for crops grown from treated seeds) or application (for other application types). Honey bees were observed collecting guttation water, but the proportion of guttation water in the overall water collection by honey bee colonies remains unclear (Joachimsmeier et al. 2011a; Nikolakis et al. 2014). Counts of dead bees at study hives did not significantly increase with exposure to treated crops during guttation periods, and no long-term effects on colony health could be observed in studies where honey bee colonies were assessed over longer time periods (Joachimsmeier et al. 2011a; Nikolakis et al. 2014).

Studies of water foraging in honey bees may provide more clarity about the potential influx of guttation water to honey bee hives, as preferences in water foraging remain unclear. Honey bees may prefer water containing minerals, as can be studied by presenting bee colonies with water sources containing minerals and water without solutes. Bonoan et al. (2017) found a slight preference of bees for water containing sodium chloride (salt) over deionized water in such a study design. Guttation water contains low amounts of solutes (Pistorius et al. 2011; Singh 2013), and would not appeal to a preference for salt. Reetz et al. 2012 introduced a method to assess water foraging activity of a hive by determining the honey stomach content of foragers returning to the hive.
Field studies conducted with honey bee colonies do not reliably point to impacts on colony health due to placement next to a treated field during flowering (Pilling et al. 2013, Cutler et al. 2014; Balfour et al. 2017; Woodcock et al. 2017) or during guttation periods (Pistorius et al. 2011; Joachimsmeier et al. 2011a; Nikolakis et al. 2014). While residues of neonicotinoid insecticides were detected in samples of honey bee hive products across agricultural landscapes (Lawrence et al. 2016), colony-level risks from the exposure appear to be low. A recent field study found honey bee colonies in better condition in agricultural landscapes (dominated by corn fields) as compared to landscapes dominated by forest (Sponsler and Johnson 2015).

We conclude from our review that guttation water is unlikely to constitute a high risk to honey bee colonies if considered as the sole exposure route. However, toxic levels can occur in guttation fluid from certain crops, particularly corn. According to our review and the previous review by Pistorius et al. (2011), ranges of neonicotinoid residue levels in guttation water from various treated crops are available, but water foraging preferences of honey bees are not well understood. We agree with the recommendation in the reviewed literature that water foraging mechanisms in honey bees (timing of water needs and preferences for water sources) would need to be better understood to achieve higher certainty about how much contaminated guttation water is potentially collected by honey bee colonies. The call for more research on this topic is underlined by the frequent statement of guttation water as potential relevant exposure route of honey bees to neonicotinoids in recent scientific publications and recommendations by regulatory agencies.

\section{ACKNOWLEDGEMENTS}

We want to thank Gregg Hancock, members of the Pollinator Research Task Force and a reviewer for comments on a previous version of the manuscript, and Jennifer Jackson for manuscript formatting. 


\section{AUTHORS' CONTRIBUTION}

AS and BO developed the review goals; AS and BK contributed equally to the literature review and manuscript preparation; all authors contributed to read and approved the final version.

\section{FUNDING INFORMATION}

Funding for the work on this review and the preparation of the manuscript was provided by the Pollinator Research Task Force (PRTF).

\section{COMPLIANCE WITH ETHICAL STANDARDS}

Conflict of interest The authors declare that the work on the review was funded by the Pollinator Research Task Force (PRTF), an industry interest group of crop protection companies.

La guttation des végétaux comme voie potentielle d'exposition aux pesticides chez les abeilles mellifères: une revue de la littérature récente.

Guttation/abeilles/évaluation des risques liés aux pesticides/néonicotinoïdes .

Guttationswasser von Pflanzen als mögliche Quelle für eine Pestizid-Exposition von Honigbienen: Ein Review der neueren Veröffentlichungen.

\section{Guttation / Honigbienen / Pestizid Risikoabschätzung / Neonikotinoide.}

\section{REFERENCES}

Balfour N. J., Al Toufailia H., Scandian L., Blanchard H. E., Jesse M. P., Carreck N. L., Ratnieks W. (2017) Landscape scale study of the net effect of proximity to a neonicotinoid-treated crop on bee colony health. Environ. Sci. Technol. 51 (18), 10825-10833

Blacquière, T., Smagghe, G., van Gestel, C. A. M., Mommaerts, V. (2012) Neonicotinoids in bees: a review on concentrations, side-effects and risk assessment. Ecotoxicology 21 (4), 973-992

Bonmatin, JM., Giorio, C., Girolami, V., Goulson, D, Kreutzweiser, D. P., et al. (2015) Environmental fate and exposure; neonicotinoids and fipronil. Environ. Sci. Pollut. R. 22 (1), 35-67
Bonoan, R. E., Tai, T. M., Tagle Rodriguez, M., Feller, L., Daddario, S. R., Czaja, R. A., O'Connor, L. D., Burruss, G., Starks, P. T. (2017) Seasonality of salt foraging in honey bees (Apis mellifera). J. Ecol. Entomol. 42, 195-201

Clermont, A., Eickermann, M., Kraus, F., Hoffmann, L., Beyer, M. (2015) Correlations between land covers and honey bee colony losses in a country with industrialized and rural regions. Sci. Total Environ. 532, 1-13

Codling, G., Al Naggar, Y., Giesy, J.P., Robertson, A.J. (2016) Concentrations of neonicotinoid insecticides in honey, pollen and honey bees (Apis mellifera L.) in central Saskatchewan, Canada. Chemosphere 144, 2321-2328

Cutler, G. C., Scott-Dupree, C. D., Sultan, M., McFarlane, A. D., Brewer, L. (2014) A large-scale field study examining effects of exposure to clothianidin seedtreated canola on honey bee colony health, development, and overwintering success. Peer J, DOI:https://doi.org/10.7717/peerj.652

European Food Safety Authority (EFSA). (2013) EFSA guidance document on the risk assessment of plant protection products on bees (Apis mellifera, Bombus spp. and solitary bees). EFSA Journal, 11 (7): 2683295. DOI: https://doi.org/10.2903/j.efsa.2013.3295

Fairbrother, A., Purdy, J., Anderson, T., Fell, R. (2014) Risks of neonicotinoid insecticides to honeybees. Environ. Toxicol. Chem. 33 (4), 719-731

Girolami, V., Mazzon, L., Squartini, A., Mori, N., Marzaro, M., Bernardo, A. D., Greatti, M., Giorio, C., Tapparo, A. (2009) Translocation of neonicotinoid insecticides from coated seeds to seedling guttation drops: a novel way of intoxication for bees. J. Econ. Entomol. 102 (5), 1808-15

Hoffmann, E. J., Castle, S. J. (2012) Imidacloprid in melon guttation fluid: a potential mode of exposure for pest and beneficial organisms. J. Econ. Entomol. 105 (1), $67-71$

Joachimsmeier, I., Pistorius, J., Heimbach, U., Schenke, D., Kirchner, W. (2011a) Water collection by honey beeshow far will foragers fly to use water sources like guttation drops? a first distance trial using cereals and oilseed rape, in: 11th International Symposium of the ICP-BR Bee Protection Group, Wageningen (The Netherlands), 2-4 November, 2011, JuliusKühn-Archiv, 437, 82-86

Joachimsmeier I., Pistorius, J., Heimbach, U., Schenke, D., Zwerger P., Kirchner, W. (2011b) Frequency and intensity of guttation events in different crops in Germany, in: 11 th International Symposium of the ICP-BR Bee Protection Group, Wageningen (The Netherlands), 2-4 November, 2011, Julius-Kühn-Archiv, 437, 87-90.

Kovac H., Stabentheiner, A., Schmaranzer, S. (2010) Thermoregulation of water foraging honeybees - balancing of endothermic activity with radiative heat gain and functional requirements. J. Insect Physiol. 56 (12), 1834-1845

Krupke, C. H., Long, E. Y. (2015) Intersections between neonicotinoid seed treatments and honey bees. Curr. Opin. Insect Sci. 10, 8-13 
Kühnholz, S., Seeley, T. D. (1997) The control of water collection in honey bee colonies. Behav. Ecol. Sociobiol. 41 (6), 407-22

Larson, J. L., Redmond, C. T., Potter, D. A. (2015) Mowing mitigates bioactivity of neonicotinoid insecticides in nectar of flowering lawn weeds and turfgrass guttation. Environ. Toxicol. Chem. 34 (1), 127-132

Lawrence, T. J., Culbert, E. M., Felsot, A. S., Hebert, V. R., Sheppard, W. S. (2016) Survey and risk assessment of Apis mellifera (Hymenoptera: Apidae) exposure to neonicotinoid pesticides in urban, rural, and agricultural settings, J. Econ. Entomol. 109 (2), 520-528

Lindauer, M. (1955) The water economy and temperature regulation of the honeybee colony. Bee World 36 (5), 81-92

Lundin, O., M. Rundlof, Smith, H. G., Fries, I., Bommarco, R. (2015) Neonicotinoid insecticides and their impacts on bees: a systematic review of research approaches and identification of knowledge gaps. PLoS ONE, DOI:https://doi.org/10.1371/journal.pone.0136928

Marzaro, M., Vivan, L., Targa, A., Mazzon, L., Mori, N., et al. (2011) Lethal aerial powdering of honey bees with neonicotinoids from fragments of maize seed coat. B. Insectol. 64 (1), 119-126

McCurdy, J.D., Held, D.W., Gunn, J.M., Barickman, T.C. (2017) Dew from warm-season turfgrasses as a possible route for pollinator exposure to lawnapplied imidacloprid. Crop, Forage \& Turfgrass Management 3, DOI:https://doi.org/10.2134 /cftm2016.09.0063

Neumann, P., Carreck, N. L. (2010) Honey bee colony losses. J. Apicult. Res. 49 (1), 1-6

Nikolakis, A., Keppler, J., Miles, M., Schoening, R. (2014) Neonicotinoid seed treatment products - occurrence and relevance of guttation for honeybee colonies, in: 12th International Symposium of the ICP-PR Bee Protection Group, Ghent (Belgium), 15-17 September, 2014, Julius-Kühn-Archiv, 450, 160-167.

Ostwald M. M., Smith, M. L., Seeley T. D. (2016) The behavioral regulation of thirst, water collection and water storage in honey bee colonies. J. Exp. Biol. 219, 2156-2165

Pilling E., Campbell, P., Coulson, M., Ruddle, N., Tornier, I. (2013) A four-year field program investigating longterm effects of repeated exposure of honey bee colonies to flowering crops treated with thiamethoxam. PLoS ONE, DOI:https://doi.org/10.1371/journal. pone. 0077193

Pistorius, J., Brobyn, T., Campbell, P., Forster, R., Lortsch, J-A., et al. (2011) Assessment of risks to honey bees posed by guttation, in: 11th International Symposium of the ICP-BR Bee Protection Group, Wageningen (The Netherlands), 2-4 November, 2011, JuliusKühn-Archiv, 437, 199-208

Reetz, J.E., Zühlke, S., Spiteller, M., Wallner, K. (2012) A method for identifying water foraging bees by refractometer analysis: a spotlight on daily and seasonal water collecting activities of Apis mellifera L. J. Verbrauch. Lebensm. 7 (4), 283-290
Reetz, J. E., Schulz, W., Seitz, W., Spiteller, M., Zühlke, S., Armbruster, W., Wallner, K. (2015) Uptake of neonicotinoid insecticides by water-foraging honey bees (Hymenoptera: Apidae) through guttation fluid of winter oilseed rape. J. Econ. Entomol. 109 (1), $31-40$

Rortais, A., Arnold, G., Dorne, J-L., More, S. J., Sperandio, G., Streissl, F., Szentes, C., Verdonck, F. (2017) Risk assessment of pesticides and other stressors in bees: Principles, data gaps and perspectives from the European Food Safety Authority. Sci. Total Environ. 587588, 524-537.

Sanchez-Bayo, F., Goka, K. (2014) Pesticide residues and bees - a risk assessment. PLoS ONE, DOI:https://doi. org/10.1371/journal.pone.0094482

Seeley, T. D. (1995) The Wisdom of the Hive: The Social Physiology of Honey Bee Colonies. Harvard University Press, Cambridge, Massachusetts

Seitz, N., Traynor, K. S., Steinhauer, N., Rennich, K., Wilson, M. E., Ellis, J. D., Rose, R., Tarpy, D. R., Sagili, R. R., Caron, D. M., Delaplane, K. S., Rangel, J., Lee, K., Baylis, K., Wilkes, J. T., Skinner, J. A., Pettis, J. S., vanEngelsdorp, D. (2015) A national survey of managed honey bee 2014-2015 annual colony losses in the USA. J. Apicult. Research 54, 292-304

Singh, S. (2013) Guttation: path, principles and functions. Aust. J. Bot. 61, 497-515

Sponsler, D. B., Johnson, R. M. (2015) Honey bee success predicted by landscape composition in Ohio, USA. PeerJ, DOI:https://doi.org/10.7717/peerj.838

Tapparo, A., Giorio, C., Marzaro, M., Marton, D., Soldà, L., Girolami, V. (2011) Rapid analysis of neonicotinoid insecticides in guttation drops of corn seedlings obtained from coated seeds. J. Environ. Monit. 13 (6), 1564 1568

Thompson, H. M. (2010) Risk Assessment for Honey Bees and Pesticides-Rrecent Developments and 'new Issues.' Pest Manag. Sci. 66 (11), 1157-62

U.S. Environmental Protection Agency (USEPA). (2012) White paper in support of the proposed risk assessment process for bees. Environmental Fate and Effects Division. Office of Pesticide Program. Washington, D.C. [o n $1 \mathrm{ine}$ ] h t t p : / / w w w c d p r. c a . gov/docs/emon/surfwtr/presentations/epa_whitepaper. pdf (accessed on 1 May 2017)

U.S. Environmental Protection Agency (USEPA). (2014) Guidance for assessing pesticide risks to bees. Office of Chemical Safety and Pollution Prevention Office of Pesticide Programs Environmental Fate and Effects Division, Environmental Protection Agency, Washington DC; Health Canada Pest Management Regulatory Agency, Ottawa, CN; California Department of Pesticide Regulation, Sacramento, CA.

Wirtz, I. P., Hauer-Jákli, M., Schenke, D., Ladewig, E., Märländer, B., Heimbach, U., Pistorius, J. (2018) Investigations on neonicotinoids in guttation fluid of seed treated sugar beet: Frequency, residue levels and discussion of the potential risk to honey bees. Crop Prot. 105, 28-34 
Wood, T. J., Goulson, D. (2017) The environmental risks of neonicotinoid pesticides: a review of the evidence post 2013. Environ. Sci. Pollut. Res. 24 (21), 17285-17325
Woodcock, B. A., Bullock, J. M., Shore, R. F., Heard, M. S., Pereira, M. G., et al. (2017) Country-specific effects of neonicotinoid pesticides on honey bees and wild bees. Science 356, 1393-1395 